Mycology

\title{
Candida tropicalis biofilm's matrix-involvement on its resistance to amphotericin B
}

\author{
Tânia Fernandes, Sónia Silva *, Mariana Henriques \\ Centre of Biological Engineering, Laboratório de investigação em Biofilmes Rosário Oliveira, University of Minho, Campus de Gualtar, 4710-057, Braga, Portugal
}

\section{A R T I C L E I N F O}

\section{Article history:}

Received 2 February 2015

Received in revised form 19 June 2015

Accepted 22 June 2015

Available online 23 June 2015

\section{Keywords:}

Candida tropicalis

Biofilms

Amphotericin B

Resistance

Matrix

\begin{abstract}
A B S T R A C T
Candida tropicalis has emerged as one of the most prevalent fungal pathogens, and its ability to form biofilms has been considered one of the most important virulence factors, since they represent high tolerance to antifungal agents. However, the mechanisms of biofilm resistance to antifungal agents remain poorly understood. Thus, the main goal of this study was to infer about the ability of amphotericin B (AMB) to control and combat C. tropicalis biofilms. Additionally, it was also intended to determine the influence of matrix components in biofilm resistance. AMB was unable to totally prevent biofilm formation and to eradicate $C$. tropicalis preformed biofilms. Moreover, AMB led to a significant increase of the biofilm production due to an augment of the total protein and carbohydrate contents of the matrix. The $C$. tropicalis biofilm matrix assumes an important role on its resistance to AMB.
\end{abstract}

(c) 2015 Elsevier Inc. All rights reserved.

\section{Introduction}

Candidiasis is the most prevalent opportunistic fungal infection on humans and, as such, a major public health problem (Silva et al., 2012). In the recent decades, candidiasis have been associated to Candida tropicalis, and it has been reported as an important causative agent of the bloodstream and urinary tract infections in hospitalized patients, causing high mortality and morbidity (Negri et al., 2010, 2012; Silva et al., 2012).

During the last decades, the levels of candidiasis due to $C$. tropicalis have been increasing, and it could be attributed to the greater use of antifungal agents nowadays and over long periods of time, which enabled an increase of resistance of $C$. tropicalis to certain antifungal agents, specifically to amphotericin B (AMB) (Muñoz et al., 2011; Negri et al., 2012). In clinical practice, $A M B$, belonging to the polyene group, is 1 of the antifungal agents most commonly used to treat candidiasis (Silva et al., 2012; Williams et al., 2011).

Biofilms have been considered the most prevalent growth form of microorganisms and 1 of the virulence factors that mostly contribute to the pathogenicity of Candida species (Negri et al., 2012; Silva et al., 2011, 2012). Moreover, from the clinical perspective, the most important feature of Candida biofilms is its role in increasing tolerance to conventional antifungal therapy (Silva et al., 2012).

However, despite that there is some knowledge about the effect of AMB against $C$. tropicalis planktonic cells (Negri et al., 2010; Silva et al., 2012), there is a lack of information concerning its role on $C$. tropicalis biofilms. Thus, the main aim of this work was to infer about

\footnotetext{
* Corresponding author. Tel.: +351-253604401; fax: +351-253604424.

E-mail address: soniasilva@deb.uminho.pt (S. Silva).
}

the AMB ability to control and combat $C$. tropicalis biofilms and to determine the influence of matrix in the biofilm resistance.

\section{Materials and methods}

\subsection{Organisms and growth conditions}

A total of 3 different $C$. tropicalis strains were used during this work: 1 oral strain (AG1), from the biofilm group of the Centre of Biological Engineering, originally isolated from Clinic Dentistry, Congregados, Braga, Portugal; 1 urinary tract strain (519468), recovered from patients of the Hospital of S. Marcos, Braga, Portugal; and 1 vaginal strain (12), obtained from the archive collection of the University of Maringá, Brazil. The identification of all isolates was confirmed using CHROMagar Candida medium (CHROMagar, Paris, France) and by polymerase chain reaction (PCR)-based sequencing using specific primers (ITS1 and ITS4) against the $5.8 \mathrm{~S}$ subunit gene reference. Genomic deoxyribonucleic acid (DNA) was extracted following previously described procedures (Williams et al., 1995). The PCR products were sequenced using the ABI-PRISM Big Dye terminator cycle sequencing kit (Perkin Elmer; Applied Biosystems, Warrington, UK). For all experiments, C. tropicalis strains were subcultured on Sabouraud dextrose agar medium (SDA; Merck, Darmstadt, Germany) for $48 \mathrm{~h}$ at $37^{\circ} \mathrm{C}$.

\subsection{Minimum inhibitory concentrations determination}

MICs of $C$. tropicalis strains were determined for the antifungal agent AMB (Pfizer, NY, USA), using the microdilution method, in accordance with the guidelines of the Clinical and Laboratory Standards Institute (CLSI) (Pfaller et al., 2008). The AMB concentrations tested were 0.5, $1,1.5,2,2.5,4$, and $6 \mathrm{mg} / \mathrm{L}$. 
To confirm the MICs values, cell suspensions were recovered to a new well microplate, and serial dilutions were plated in SDA at $37^{\circ} \mathrm{C}$. After $24 \mathrm{~h}$ of incubation, the total number of colony-forming units (CFUs) was determined, and the results were presented as $\log _{10}$ CFUs per milliliter ( $\left.\log _{10} \mathrm{CFUs} / \mathrm{mL}\right)$.

Assessments of the response profiles with different antifungal agents were performed in triplicate and on 3 different occasions.

\subsection{Biofilm formation}

An inoculum of each yeast strain, obtained from SDA plates, was resuspended in $30 \mathrm{~mL}$ of Sabouraud dextrose broth medium (SDB; Merck, Darmstadt, Germany) and incubated for $16-18 \mathrm{~h}$ at $37^{\circ} \mathrm{C}$, under agitation at $120 \mathrm{rpm}$. Then, cells were harvested by centrifugation at $5000 \mathrm{~g}$ for $10 \mathrm{~min}$ at $4{ }^{\circ} \mathrm{C}$ and washed twice with phosphate-buffered saline (PBS), pH 7.0, $0.1 \mathrm{~mol} / \mathrm{L}$. The pellets were then resuspended in PBS. Prior to being used in each experiment, the cellular density adjusted to $2 \times 10^{5}$ cells $/ \mathrm{mL}$, in Roswell Park Memorial Institute 1640 medium (RPMI; Sigma, St. Louis, MO, USA) supplemented with $2 \%$ of glucose, using a Neubauer counting chamber.

\subsubsection{Influence of $A M B$ in biofilm formation}

In order to study the effect AMB on $C$. tropicalis biofilm formation, different concentrations of the agent $(0.5,1$, and $2 \mathrm{mg} / \mathrm{L})$ were prepared in RPMI medium and added at the beginning of the biofilm process formation. AMB solutions were prepared with twice the concentration tested in RPMI medium, from stock solutions of $1000 \mathrm{mg} / \mathrm{L}$ in dimethyl sulfoxide (Sigma). Cells were prepared as described above, and each well of a 96-well microplate (Orange Scientific, Braine-l' Alleud, Belgium) was filled with $100 \mu \mathrm{L}$ of the antifungal agent and $100 \mu \mathrm{L}$ of the standardized cell suspension. Controls were also performed with Candida cells without antifungal agents. The microplates were incubated for $48 \mathrm{~h}$ at $37^{\circ} \mathrm{C}$ and $120 \mathrm{rpm}$. The experiments were repeated in triplicate in 3 different occasions.

\subsubsection{Influence of $A M B$ on preformed biofilms}

In order to test the AMB ability to destroy preformed biofilms, C. tropicalis biofilms were formed during $24 \mathrm{~h}$ at $37^{\circ} \mathrm{C}$ and $120 \mathrm{rpm}$, in RPMI medium. For that, $200 \mu \mathrm{L}$ of each Candida suspension, containing $1 \times 10^{5}$ cells $/ \mathrm{mL}$ in RPMI medium supplemented with $2 \%$ of glucose, was added to the respective 96 -well microplates. After the biofilm formation, the entire medium was aspirated, and different concentrations of $\operatorname{AMB}(0.5,1,2$, and $10 \mathrm{mg} / \mathrm{L})$ prepared in RPMI medium were added to the specific wells. The microplates were incubated for additional 48 h at $37^{\circ} \mathrm{C}$ and $120 \mathrm{rpm}$. Controls were also performed with Candida cells without antifungal agents. The experiments were repeated in triplicate on 3 different occasions.

\subsection{Biofilm analyses}

\subsubsection{Biofilm total biomass}

Biofilm total biomass was quantified by crystal violet (CV) staining (Silva et al., 2009). For that, the medium was totally aspirated, and the nonadherent cells were removed by washing the biofilms once with $200 \mu \mathrm{L}$ of PBS. The biofilm was fixed with $200 \mu \mathrm{L}$ of methanol $(100 \% \mathrm{v} / \mathrm{v})$, which was removed after $15 \mathrm{~min}$ of contact. The microplates were allowed to dry at room temperature, and $200 \mu \mathrm{L}$ of CV $(1 \% \mathrm{v} / \mathrm{v})$ was added to each well and incubated for additional $5 \mathrm{~min}$. The wells were then gently washed twice with $200 \mu \mathrm{L}$ of sterile ultrapure water, and $200 \mu \mathrm{L}$ of acetic acid (33\% v/v) was added to release and dissolve the absorbed stain. The absorbance of the obtained solution was read in triplicate in a microplate reader at $570 \mathrm{~nm}$. The results were presented as absorbance per unit of area $\left(\mathrm{Abs}_{570 \mathrm{~nm}} / \mathrm{cm}^{2}\right)$.

\subsubsection{Biofilm cultivable cells}

The number of cultivable cells in biofilms was determined by the enumeration of CFUs. For that, the medium was aspirated, and the biofilms were washed once with $200 \mu \mathrm{L}$ of PBS to remove nonadherent cells. Then, the biofilm was scraped from the 96-well microplates, and the suspensions were vigorously vortexed for 2 min to disaggregate cells from the matrix. In addition, in order to confirm the complete removal of the biofilms from the wells, after biofilm scraping, a CV staining was performed. Serial 10-fold dilutions in PBS were plated in SDA and incubated at $37{ }^{\circ} \mathrm{C}$ for $24 \mathrm{~h}$. The results were presented as the total of CFUs per unit of area $\left(\log _{10} \mathrm{CFUs} / \mathrm{cm}^{2}\right)$.

\subsubsection{Biofilm structure}

The structure of preformed biofilms was examined by scanning electron microscopy (SEM). For the conditions tested (absence or presence of $2 \mathrm{mg} / \mathrm{L}$ of AMB), biofilms were formed into 24-well microplates (Orange Scientific, Braine-l' Alleud, Belgium) with an inoculum of $1 \mathrm{~mL}$ of yeast cell suspension containing $1 \times 10^{5}$ cells $/ \mathrm{mL}$ in RPMI medium, as described previously.

The samples were dehydrated with increasing percentages of ethanol (using 70\% ethanol for $10 \mathrm{~min}$, 95\% ethanol for $10 \mathrm{~min}$, and $100 \%$ ethanol for $20 \mathrm{~min}$ ) and air dried for additional $20 \mathrm{~min}$. Samples were kept in a desiccator until the base of the wells was mounted onto aluminum stubs, sputter coated with gold, and observed with an S-360 SEM.

\subsection{Biofilm matrix composition analysis}

\subsubsection{Matrix extraction method}

Biofilms for analysis of matrix compounds were formed in 24-well microplates, in order to obtain a higher amount of biomass. As such, an inoculum of $1 \mathrm{~mL}$ of yeast cell suspension $\left(1 \times 10^{5}\right.$ cells $/ \mathrm{mL}$ in RPMI medium) was added to each well, and biofilms were formed as described previously for preformed biofilms. After $24 \mathrm{~h}$, the medium was aspirated, and $2 \mathrm{mg} / \mathrm{L}$ of AMB was added to the specific wells and incubated for more $48 \mathrm{~h}$ at $37^{\circ} \mathrm{C}$ and $120 \mathrm{rpm}$. Controls were also performed with Candida cells growing in the absence of AMB. After $48 \mathrm{~h}$, the biofilms were washed once with $1 \mathrm{~mL}$ of ultrapure water to remove nonadherent cells, and the biofilms were scraped from the wells and resuspended in $500 \mu \mathrm{L}$ of ultrapure water. The suspensions were vortexed for $2 \mathrm{~min}$ and filtered through a 0.20 - $\mu \mathrm{m}$ filter to evaluate the dry weight of the biofilm. The remaining suspension was sonicated for $30 \mathrm{~s}$ at $30 \mathrm{~W}$, vortexed for $2 \mathrm{~min}$, and centrifuged at $5000 \mathrm{~g}$ for $10 \mathrm{~min}$ at $4{ }^{\circ} \mathrm{C}$, in order to recover only the matrix, which was stored at $-20^{\circ} \mathrm{C}$ before analysis. The experiments were performed in triplicate and in 3 independent assays.

\subsubsection{Proteins and carbohydrates quantification}

The proteins' content of the biofilm matrix of $C$. tropicalis strains was measured using the bicinchoninic acid kit (Thermo Fisher Scientific, Rockford, IL, USA), using bovine serum albumin as standard. The absorbance was determined in a microplate reader at $562 \mathrm{~nm}$.

The total carbohydrate content of the biofilm matrix of $C$. tropicalis strains was estimated according to the procedure of DuBois et al. (1956), using glucose as standard. The absorbance was read in a 96-well microplate reader at $490 \mathrm{~nm}$.

\subsection{Statistical analysis}

Statistical analysis was performed using GraphPad Prism 6 software for Windows. The results were compared using a 2-way analysis of variance with the Bonferroni post hoc test. All tests were performed with a $95 \%$ confidence level.

Table 1

C. tropicalis MICs obtained with AMB

\begin{tabular}{lc}
\hline C. tropicalis strains & MICs $(\mathrm{mg} / \mathrm{L})$ \\
\hline AG1 & $4-6$ \\
12 & $4-6$ \\
19468 & $2.5-4$ \\
\hline
\end{tabular}


A

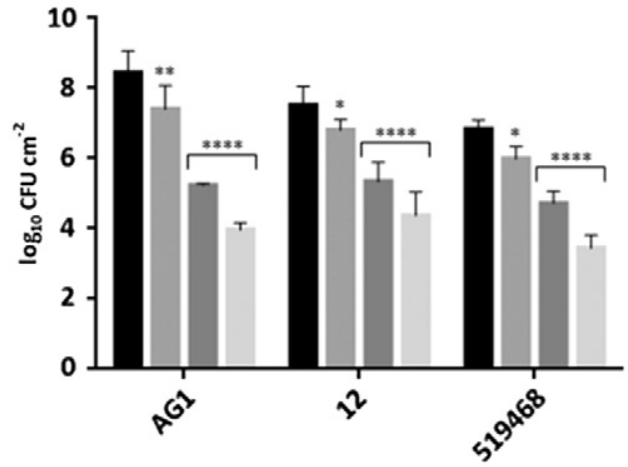

C. tropicalis strains

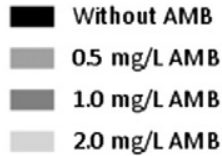

B

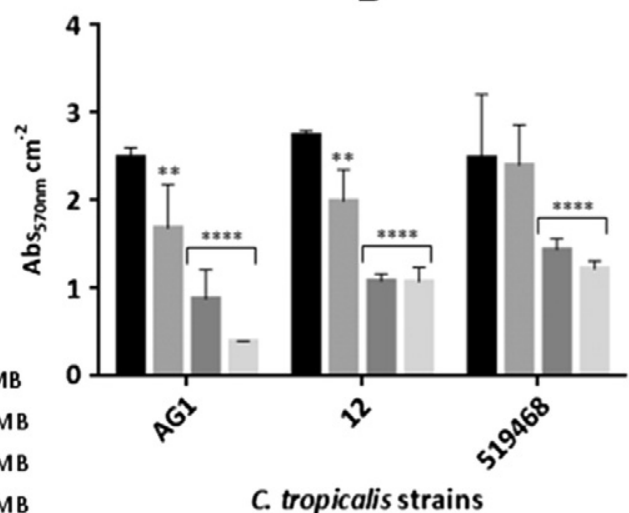

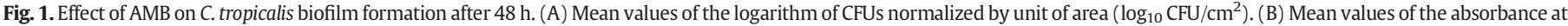
$570 \mathrm{~nm}$ normalized by unit of area $\left(\mathrm{Abs}_{570 \mathrm{~nm}} / \mathrm{cm}^{2}\right)$. Error bars indicate the SD. ${ }^{*},{ }^{* *}$, and ${ }^{* * * *}$ correspond to $P<0.05, P<0.01$, and $P<0.0001$, respectively.

\section{Results}

\subsection{Effect of the AMB on C. tropicalis planktonic cells}

The results revealed that all $C$. tropicalis strains were resistant to AMB according to the MIC breakpoint of CLSI $(>2 \mathrm{mg} / \mathrm{L})$ (Table 1$)$. The C. tropicalis strain that showed the lowest value of MIC $(2.5-4 \mathrm{mg} / \mathrm{L})$ was the clinical isolate from the urinary tract, C. tropicalis 519468.

\subsection{Amphotericin B effect on C. tropicalis biofilms}

\subsubsection{Influence of $A M B$ on biofilm formation}

The results revealed significant reductions in the number of viable cells of the 3 strains (Fig. 1A) and in total biomass values (Fig. 1B) in the presence of the higher concentrations of AMB ( 1 and $2 \mathrm{mg} / \mathrm{L}$ ), compared to the control condition $(P<0.0001)$. Moreover, it was also verified that there is a significant reduction on biofilm formation (in terms of total biomass and number of cultivable cells) in the presence of the lowest concentration of AMB $(0.5 \mathrm{mg} / \mathrm{L})$, for the 3 C. tropicalis strains studied (Fig. $1 A$ and $B$, respectively), compared to biofilms formed in the absence of the AMB $(P<0.05$ or $P<0.01)$, except in the case of the total biomass for C. tropicalis 519468 (Fig. 1B).

\subsubsection{Amphotericin B effect against preformed biofilms}

In can be observed that the effect of AMB against $C$. tropicalis preformed biofilms (Fig. 2) is not so notorious as the effect on biofilm formation (Fig. 1). In fact, only the highest concentration of AMB tested
(10 mg/L) was capable of causing a significant reduction in the number of viable cells (Fig. $2 \mathrm{~A}$ ) but only for $C$. tropicalis $12(P<0.01)$ and C. tropicalis $519468(P<0.05)$ biofilms. It is important to address that the treatment of preformed biofilms with AMB resulted in an increase of the total biomass values (Fig. 2B), specifically for the lowest concentrations of $\operatorname{AMB}(0.5,1$, and $2 \mathrm{mg} / \mathrm{L})$ in the case of $C$. tropicalis AG1, 12, and 519468, compared to the control $(P<0.01$ only for 0.5 and $1 \mathrm{mg} / \mathrm{L}$ of AMB, $P<0.0001$ and $P<0.001$, respectively).

\subsection{Effect of $A M B$ on C. tropicalis biofilm structure and matrix composition}

SEM analysis was performed to examine the effect of the AMB on the structure of $C$. tropicalis preformed biofilms. As such, each biofilm was treated with AMB ( $2 \mathrm{mg} / \mathrm{L}$ ) (Fig. 3, II) and compared with the respective untreated biofilm (Fig. 3, I). It was evident that $C$. tropicalis biofilms are formed by different yeast morphologies in a strain-dependent manner (Fig. 3, I). C. tropicalis AG1 biofilm is constituted by higher quantity of filamentous forms (Fig. 3A, I) presenting a more continuous layer, while C. tropicalis 12 (Fig. 3B, I) and C. tropicalis 519468 (Fig. 3C, I) presented biofilms with lower quantity of filamentous forms.

Interestingly, it was observed that $C$. tropicalis biofilms, when treated with AMB (Fig. 3, II), presented a more compact and continuous structure with the cells more interlinked. In fact, after treatment of the biofilms with AMB, they appear with more compact aspect and with all cells embedded into the extracellular matrix (ECM) (Fig. 3, I). Moreover, in the presence of AMB, C. tropicalis biofilms presented a reduction in the number of filamentous forms (Fig. 3, II).
A

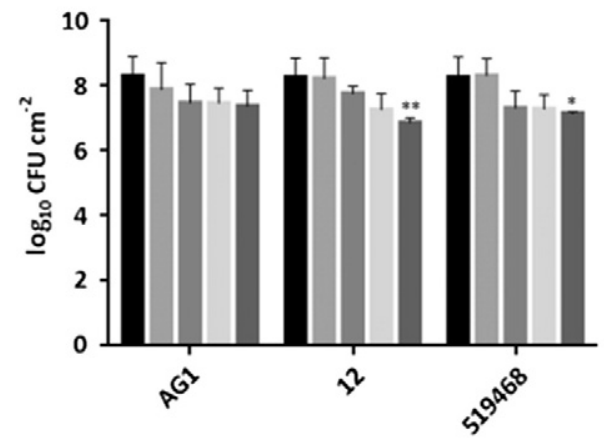

C. tropicalis strains

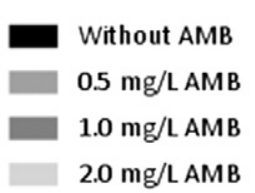

$2.0 \mathrm{mg} / \mathrm{L} \mathrm{AMB}$
B

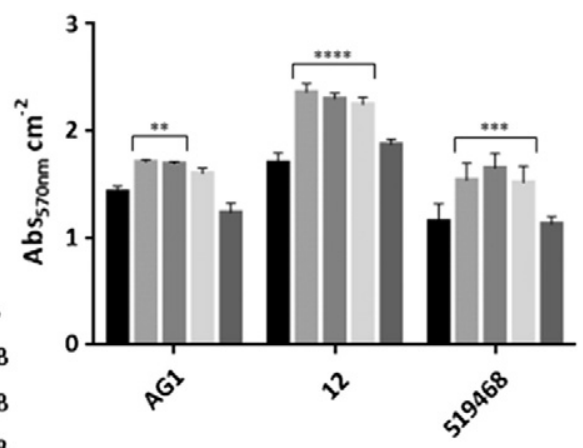

C. tropicalis strains

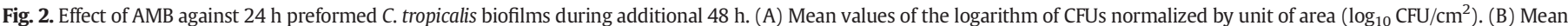

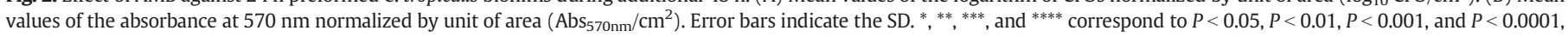
respectively. 
A

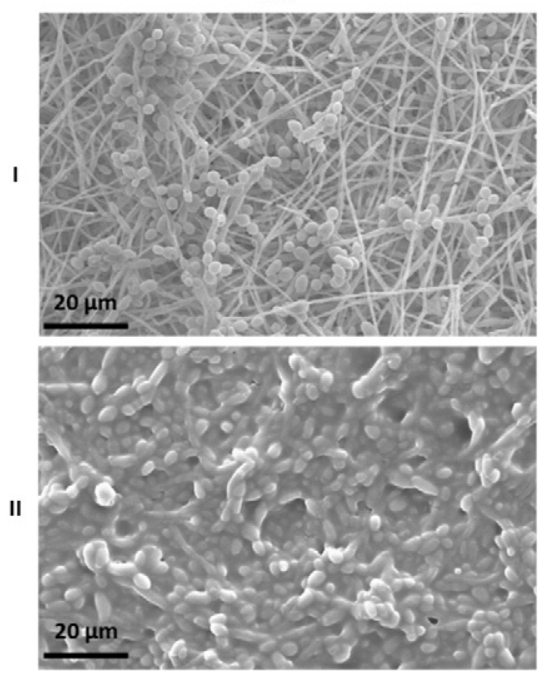

B

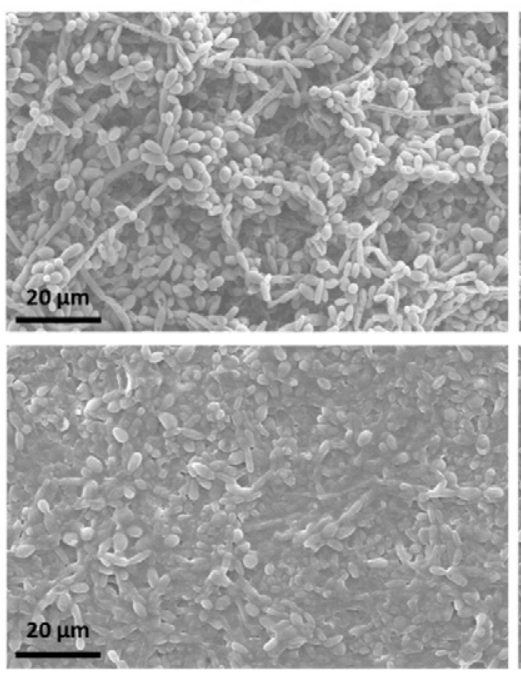

C

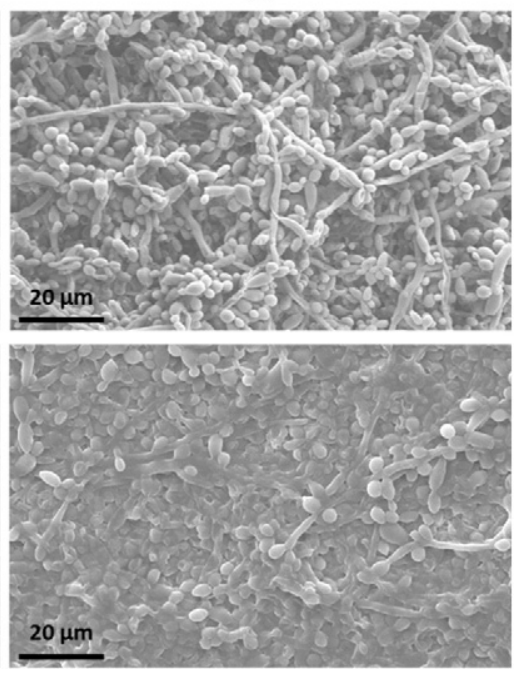

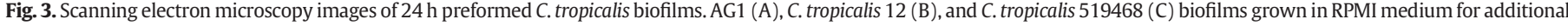
$48 \mathrm{~h}$ (I) in the absence of amphotericin B and (II) in the presence of $2 \mathrm{mg} / \mathrm{L}$ of the AMB. The bar in the images corresponds to $20 \mu \mathrm{m}$. Magnification $\times 1000$.

In order to infer about the role of AMB in the C. tropicalis biofilm matrix production and composition, the total protein and carbohydrate content were also determined (Table 2).

Concerning the total protein content, the results showed a significant increase in the biofilm matrices treated with $2 \mathrm{mg} / \mathrm{L}$ of AMB for the $3 C$. tropicalis strains tested $(P<0.0001$ for $C$. tropicalis AG1 and C. tropicalis 12 and $P<0.001$ for $C$. tropicalis 519468). It should be noted that the $C$. tropicalis 519468 biofilm's matrices presented approximately half of the protein composition, compared to $C$. tropicalis AG1 and $C$. tropicalis 12, in the absence and presence of AMB.

Regarding the results obtained with respect to the analysis of the carbohydrate content, an increase after biofilm treatment with $2 \mathrm{mg} / \mathrm{L}$ of AMB, in the case of the C. tropicalis AG1 and C. tropicalis 519468, was also observed, in comparison to the absence of $\mathrm{AMB}(P<0.01)$. In contrast, $C$. tropicalis 12 biofilm matrices showed a significant reduction in the carbohydrates values $(P<0.001)$. Moreover, likewise to protein content, $C$. tropicalis 519468 showed the lower carbohydrate content in the absence and presence of AMB, in comparison to the other 2 C. tropicalis strains tested.

\section{Discussion}

C. tropicalis has been reported to be 1 of the Candida species that is most likely to cause bloodstream and urinary tract infections in hospitalized patients and also with high potential for dissemination, mobility, and mortality (Kothavade et al., 2010; Negri et al., 2010, 2012; Silva

Table 2

Effect of the AMB in the C. tropicalis preformed biofilm matrix composition in terms of protein and carbohydrate quantities.

\begin{tabular}{llll}
\hline $\begin{array}{l}\text { C. tropicalis } \\
\text { strains }\end{array}$ & $\begin{array}{l}\text { Concentration of } \\
\text { AMB }(\mathrm{mg} / \mathrm{L})\end{array}$ & $\begin{array}{l}\text { Protein quantity } \\
\left(\mathrm{mg} \text { protein } / \mathrm{g}_{\text {biofilm }}\right)\end{array}$ & $\begin{array}{l}\text { Carbohydrate quantity } \\
\left(\mathrm{mg} \text { carbohydrate } / \mathrm{g}_{\text {biofilm }}\right)\end{array}$ \\
\hline \multirow{2}{*}{$\mathrm{AG} 1$} & 0 & $17.519 \pm 1.963$ & $285.365 \pm 0.273$ \\
& 2 & $22.383 \pm 0.607^{* * * *}$ & $333.963 \pm 0.287^{* *}$ \\
12 & 0 & $14.568 \pm 1.220$ & $363.476 \pm 1.184$ \\
& 2 & $23.220 \pm 0.845^{* * * *}$ & $294.998 \pm 31.520^{* * *}$ \\
519468 & 0 & $6.304 \pm 0.085$ & $133.174 \pm 21.349$ \\
& 2 & $10.212 \pm 1.009^{* * *}$ & $190.519 \pm 0.262^{* *}$ \\
\hline
\end{tabular}

Mean \pm SD values of the proteins ( $\mathrm{mg}$ protein $/ \mathrm{g}$ dry weight biofilm) and carbohydrates ( $\mathrm{mg}$ carbohydrate/g dry weight biofilm).

** $P<0.01$, when the presence of AMB was compared to its absence.

*** $P<0.001$, when the presence of AMB was compared to its absence.

**** $P<0.0001$, when the presence of AMB was compared to its absence. et al., 2011, 2012). This is due to several virulence factors exhibited by C. tropicalis, namely, the biofilm formation ability, since the biofilms confer significant resistance to antifungal therapy and host immune responses (Negri et al., 2012; Silva et al., 2009, 2011, 2012; Williams et al., 2011). Additionally, it is known that $C$. tropicalis isolates have the ability to form compact biofilms. Thus, the main aim of this study was to infer about the AMB ability to control and combat $C$. tropicalis biofilms and to determine the role of the matrix compounds in the $C$. tropicalis biofilm resistance to $\mathrm{AMB}$.

In the clinical perspective, the most important characteristic of Candida species is their ability to form biofilms and their role in the increased tolerance to conventional antifungal therapy, since they are much more resistant to antifungal agents than planktonic cells (Donlan and Costerton, 2002; Fonseca et al., 2014; Galán-Ladero et al., 2013; Shanmughapriya et al., 2014; Silva et al., 2012). As expected, all strains were able to form biofilms and exhibited resistance to AMB but in a strain-dependent manner (Table 1). Additionally, the strain with lower MIC value is also the strain that presented the lowest ability to form biofilm. These results appear to be in agreement with previous studies involving C. tropicalis biofilms (Galán-Ladero et al., 2013; Shanmughapriya et al., 2014).

Moreover, in general, $C$. tropicalis biofilms are more resistant to AMB, when the biofilms were formed before the addition of this antifungal agent. In fact, some studies reported that $C$. tropicalis planktonic cells were susceptible to AMB, although their biofilms exhibited resistance, normally due to the synthesis of large amounts of matrix (Al-Fattani and Douglas, 2006; Bizerra et al., 2008; Kothavade et al., 2010; Negri et al., 2012; Silva et al., 2009). This fact was also described by other authors for Candida albicans and Candida glabrata biofilms (Fonseca et al., 2014; Kumamoto, 2002; Silva et al., 2012). As it is well known, mature biofilms are in cells organized into structured communities embedded within an ECM (Negri et al., 2012; Silva et al., 2009, 2011, 2012). The matrix production has been reported as a Candida response to stress conditions, namely, to the presence of antifungal agents (Al-fattani and Douglas, 2004; Silva et al., 2011, 2012). From the analysis of the results obtained (Fig. 2B), it is possible to assume that biofilm matrix may have a role in the biofilm resistance to this agent. Notwithstanding the inherent destructive nature of the preparation of samples to be observed in the SEM, with the possible loss of some cells and matrix during the dehydration process of this technique, it is possible to observe that C. tropicalis biofilms consist of a dense network of cells with a variety of cell morphologies (Fig. 3, I), presenting a mixture of yeast cells and evident filamentous morphologies, in agreement with what was already 
described (Donlan and Costerton, 2002; Silva et al., 2009, 2011). These results are in accordance with the values of total biomass obtained (Fig. 2B) and also highlight the important role of the biofilm matrix in the Candida resistance to AMB.

Generally, the biofilm matrix compounds include (in addition to water): carbohydrates, proteins, hexosamines, and phosphorus (Baillie and Douglas, 2000; Silva et al., 2009, 2012). Our results point out to the fact that $\mathrm{AMB}$, besides inducing changes in the structure of C. tropicalis biofilms (Fig. 3), can also cause alterations in their matrix composition (Table 2). It can be speculated that AMB might then trigger the protein and carbohydrate production, resulting in a well-structured and dense biofilm. Thus, it is possible to assume that the matrix increase, in particular of protein and carbohydrate contents, may contribute to the $C$. tropicalis biofilm resistance to AMB.

\section{Conclusions}

In conclusion, this work demonstrated that AMB is unable to totally prevent biofilm formation and to eradicate C. tropicalis preformed biofilms. The significant increase of the protein and carbohydrate contents in the biofilms matrices treated with AMB seems to be the main explanation to the increase of $C$. tropicalis biofilm resistance. More in vitro (medical devices) and in vivo models can be used in the future to corroborate these results.

\section{Acknowledgments}

This work was supported by the Programa Operacional, Fatores de competitividade and by national funds through Fundação para a Ciência e a Tecnologia on the scope of the projects FCT PTDC/SAU-MIC/119069/ 2010, RECI/EBB-EBI/0179/2012, and PEst-OE/EQB/LA0023/2013. The authors also thank the Project "BioHealth - Biotechnology and Bioengineering approaches to improve health quality", Ref. NORTE-07-0124FEDER-000027, co-funded by the Programa Operacional Regional do Norte (ON.2 - O Novo Norte), QREN, FEDER.

\section{References}

Al-fattani MA, Douglas LJ. Penetration of Candida biofilms by antifungal agents Antimicrob Agents Chemother 2004;48(9):3291-7. [Available from: http://www. ncbi.nlm.nih.gov/pubmed/15328087].

Al-Fattani MA, Douglas LJ. Biofilm matrix of Candida albicans and Candida tropicalis: chemical composition and role in drug resistance. J Med Microbiol 2006;55(8): 999-1008. [Available from: http://www.ncbi.nlm.nih.gov/pubmed/16849719].

Baillie GS, Douglas LJ. Matrix polymers of Candida biofilms and their possible role in biofilm resistance to antifungal agents. J Antimicrob Chemother 2000;46(3):397-403. [Available from: http://www.ncbi.nlm.nih.gov/pubmed/10980166].
Bizerra FC, Nakamura CV, Poersch C, Svidzinski TIE, Quesada RMB, Goldenberg S, et al. Characteristics of biofilm formation by Candida tropicalis and antifungal resistance. FEMS Yeast Res 2008;8(3):442-50. [Available from: http://www.ncbi.nlm.nih.gov/ pubmed/18248413].

Donlan RM, Costerton JW. Biofilms: survival mechanisms of clinically relevant microorganisms. Clin Microbiol Rev 2002;15(2):167-93. [Available from: http://www.ncbi. nlm.nih.gov/pubmed/11932229].

DuBois M, Gilles KA, Hamilton JK, Rebers PA, Smith F. Colorimetric method for determination of sugars and related substances. Anal Chem 1956;28(3):350-6. [Available from: http://pubs.acs.org/cgi-bin/doilookup/?10.1021/ac60111a017].

Fonseca E, Silva S, Rodrigues CF, Alves CT, Azeredo J, Henriques M, et al. Effects of fluconazole on Candida glabrata biofilms and its relationship with $A B C$ transporter gene expression. Biofouling 2014;30(4):447-57.

Galán-Ladero MA, Blanco MT, Hurtado C, Pérez-Giraldo C, Blanco MT. Determination of biofilm production by Candida tropicalis isolated from hospitalized patients and its relation to cellular surface hydrophobicity, plastic adherence and filamentation ability. Yeast 2013;30:331-9. [Available from: http://www.ncbi.nlm.nih.gov/pubmed/ 23775541].

Kothavade RJ, Kura MM, Valand AG, Panthaki MH. Candida tropicalis: its prevalence, pathogenicity and increasing resistance to fluconazole. J Med Microbiol 2010;59(8): 873-80. [Available from: http://www.ncbi.nlm.nih.gov/pubmed/20413622].

Kumamoto CA. Candida biofilms. Curr Opin Microbiol 2002;5(6):608-11. [Available from: http://www.ncbi.nlm.nih.gov/pubmed/12457706].

Muñoz P, Giannella M, Fanciulli C, Guinea J, Valerio M, Rojas L, et al. Candida tropicalis fungaemia: incidence, risk factors and mortality in a general hospital. Clin Microbiol Infect 2011;17:1538-45. [Available from: http://www.ncbi.nlm.nih.gov/pubmed/ 20718804]

Negri M, Martins M, Henriques M, Svidzinski TIE, Azeredo J, Oliveira R. Examination of potential virulence factors of candida tropicalis clinical isolates from hospitalized patients. Mycopathologia 2010;169(3):175-82. [Available from: http://www.ncbi.nlm. nih.gov/pubmed/19851885]

Negri M, Silva S, Henriques M, Oliveira R. Insights into Candida tropicalis nosocomial infections and virulence factors. Eur J Clin Microbiol Infect Dis 2012;31(7):1399-412. [Available from: http://www.ncbi.nlm.nih.gov/pubmed/22037823].

Pfaller MA, Chaturvedi V, Espinel-Ingroff A, Ghannoum MA, Gosey LL, Odds FC, et al. Reference method for broth dilution antifungal susceptibility testing of yeasts: approved standard-second edition. CLSI document M27-A2 (ISBN 1-56238-469-4). Clin Lab Stand Inst 2008;22(15):1-51.

Shanmughapriya S, Sornakumari H, Lency A, Kavitha S, Natarajaseenivasan K. Synergistic effect of amphotericin B and tyrosol on biofilm formed by Candida krusei and Candida tropicalis from intrauterine device users. Med Mycol 2014;52(8):853-61. [Available from: http://www.ncbi.nlm.nih.gov/pubmed/25202127].

Silva S, Henriques M, Martins A, Oliveira R, Williams D, Azeredo J. Biofilms of non-Candida albicans Candida species: quantification, structure and matrix composition. Med Mycol 2009;47(7):681-9. [Available from: http://www.ncbi.nlm.nih.gov/pubmed/ $19888800]$.

Silva S, Negri M, Henriques M, Oliveira R, Williams DW, Azeredo J. Adherence and biofilm formation of non-Candida albicans Candida species. Trends Microbiol 2011;19(5): 241-7. [Available from: http://www.ncbi.nlm.nih.gov/pubmed/21411325].

Silva S, Negri M, Henriques M, Oliveira R, Williams DW, Azeredo J. Candida glabrata, Candida parapsilosis and Candida tropicalis: biology, epidemiology, pathogenicity and antifungal resistance. FEMS Microbiol Rev 2012;36(2):288-305. [Available from: http:// www.ncbi.nlm.nih.gov/pubmed/21569057].

Williams DW, Wilson MJ, Lewis MAO, Potts AJC. Identification of Candida species by PCR and restriction fragment length polymorphism analysis of intergenic spacer regions of ribosomal DNA. J Clin Microbiol 1995;33(9):2476-9. [Available from: http:// www.ncbi.nlm.nih.gov/pubmed/7494052].

Williams DW, Kuriyama T, Silva S, Malic S, Lewis MAO. Candida biofilms and oral candidosis: treatment and prevention. Periodontol 2000 2011;55(1):250-65. [Available from: http://www.ncbi.nlm.nih.gov/pubmed/21134239]. 